\title{
SURFACTINA: PROPRIEDADES QUÍMICAS, TECNOLÓGICAS E FUNCIONAIS PARA APLICAÇÕES EM ALIMENTOS
}

Francisco Fábio Cavalcante Barros*, Cedenir Pereira de Quadros, Mário Roberto Maróstica Júnior e Gláucia Maria Pastore Departamento de Ciência de Alimentos, Faculdade de Engenharia de Alimentos, Universidade Estadual de Campinas CP 6121, 13083-862 Campinas - SP, Brasil

Recebido em 11/11/05; aceito em 31/5/06; publicado na web em 19/1/07

\begin{abstract}
SURFACTIN: CHEMICAL, TECHNOLOGICAL AND FUNCTIONAL PROPERTIES FOR FOOD APPLICATIONS. Surfactin, a lipopeptide produced by strains of Bacillus subtilis, has been proved to be a suitable biosurfactant in several applications. For many years, it has been investigated mainly for oil recovery and environmental usage. Its chemical, technological and functional characteristics turn surfactin into an attractive compound for several utilizations. In this review we emphasize some aspects of surfactin as a new food ingredient and its potential pharmaceutical and health applications.
\end{abstract}

Keywords: surfactin; food ingredients; pharmaceutical applications.

\section{INTRODUÇÃO}

Surfactante é uma palavra derivada da contração da expressão "surface active agent", termo que significa, literalmente, agente de atividade superficial. Em outras palavras, surfactante é um composto caracterizado pela capacidade de alterar as propriedades superficiais e interfaciais de um líquido ${ }^{1,2}$. O termo interface denota o limite entre duas fases imiscíveis, enquanto o termo superfície indica que uma das fases é gasosa ${ }^{1}$. Outra propriedade fundamental dos surfactantes é a tendência de formar agregados chamados micelas que, geralmente, se formam a baixas concentrações em água. A concentração mínima na qual se inicia a formação de micelas chama-se concentração micelar crítica (CMC), sendo uma importante característica de um surfactante ${ }^{1}$. Estas propriedades tornam os surfactantes adequados para uma ampla gama de aplicações industriais envolvendo: detergência, emulsificação, lubrificação, capacidade espumante, capacidade molhante, solubilização e dispersão de fases ${ }^{3}$.

A produção mundial de surfactantes excede 3 milhões de t/ano sendo que sua utilização se concentra nas indústrias de petróleo, de cosméticos, de produtos de higiene e de limpeza ${ }^{3}$, sendo que este último é o setor que utiliza a maior parte dos surfactantes produzidos como matéria-prima para fabricação de detergentes de uso doméstico ${ }^{4}$.

A grande maioria dos surfactantes disponíveis comercialmente é sintetizada a partir de derivados de petróleo. Entretanto, o aumento da preocupação ambiental entre os consumidores, combinado com novas legislações de controle do meio ambiente levou à procura por surfactantes naturais como alternativa aos produtos existentes ${ }^{4}$.

Compostos de origem microbiana que exibem atividade superficial são denominados biossurfactantes, consistindo em subprodutos de seus respectivos sistemas metabólicos ${ }^{5}$. Nas últimas décadas, diversos microrganismos têm sido relatados como produtores de vários tipos de surfactantes. A biodegradabilidade ${ }^{6,7}$ e baixa toxicidade dos biossurfactantes constituem vantagens adicionais sobre os ingredientes sintéticos e, conseqüentemente, tornam-se substitutos dos emulsificantes convencionais em alimentos e $\operatorname{cosméticos}^{6}$, originando maior apelo de mercado pelo fato desses produtos serem considerados naturais, além de apropriados para aplicação ambiental ${ }^{7}$.

*e-mail: fabiocb@fea.unicamp.br
As bactérias, juntamente com as arqueobactérias, são as maiores responsáveis pela produção destes compostos. Estes microrganismos têm sido isolados do solo, da água marinha, de sedimentos do mar e áreas contaminadas por óleos. Diversas evidências indicam que os biossurfactantes são produzidos, em alguns casos, em grande quantidade nestes ambientes. Uma delas é a presença de espuma e emulsões em áreas de derramamento de óleos em oceanos, bem como seu efeito positivo no aumento da recuperação terciária de óleo ${ }^{8}$.

Os primeiros relatos envolvendo a utilização de biossurfactantes datam de 1949, quando Jarvis e Johnson ${ }^{9}$ detectaram as atividades antibiótica e hemolítica de um ramnolipídeo, e de 1968, quando Arima e colaboradore ${ }^{10}$ descobriram a existência de um novo composto biologicamente ativo produzido por Bacillus subtilis ${ }^{9}$, o qual foi denominado surfactina devido à sua grande atividade superficial, tendo, posteriormente, sua estrutura elucidada ${ }^{11}$. Mais tarde, foi registrada a produção de biossurfactante em meios hidrofóbicos, o que levou a estudos de sua aplicação em tratamento de resíduos de petróleo $^{12}$, recuperação de petróleo ${ }^{13,14}$, biorremediação e dispersão no derramamento de óleos ${ }^{14}$.

Os biossurfactantes, de modo geral, podem ser classificados em: glicolipídeos, lipossacarídeos, lipopeptídeos, fosfolipídeos e ácidos graxos/lipídeos neutros (como os ácidos ustilágico e corinomicólico ${ }^{15}$, além de surfactantes poliméricos e surfactantes particulados ${ }^{16}$, sendo os lipopeptídeos os biossurfactantes mais efetivos $^{15}$. Os surfactantes lipoprotéicos são talvez os mais conhecidos por suas atividades antibióticas, sendo melhor caracterizados aqueles produzidos por Bacillus sp, incluindo surfactina, iturina, fengicina, liquenisina ${ }^{8}$, micosubtilisina e bacilomicina ${ }^{17}$. Esse tipo de composto se caracteriza pela existência de peptídeos ligados a ácidos graxos, sendo que a porção protéica da molécula pode ser neutra ou aniônica e os aminoácidos estão freqüentemente dispostos em uma estrutura cíclica ${ }^{8}$.

Apesar da elucidação de diversas propriedades da surfactina na década de 60 , somente nos anos 80 chamou a atenção de diversos pesquisadores como uma alternativa atraente para substituir os surfactantes sintéticos, os quais podem ser mais danosos ao ambiente $^{8}$. Surfactantes produzidos por diferentes linhagens de Bacillus subtilis, além de serem obtidos por processos menos agressivos sob o ponto de vista ambiental, apresentaram efeitos significativos na biodegradação de hidrocarbonetos alifáticos e $\operatorname{aromáticos}^{18-20}$, 
remoção de óleo de areia contaminada ${ }^{19,21}$, formação de emulsões estáveis em óleo ${ }^{21}$, bem como na degradação do pesticida endosulfan ${ }^{22}$ e biorremediação de solos altamente contaminados por zinco e cádmio ${ }^{23}$.

A indústria petrolífera era o grande mercado para biossurfactantes até a década de 90, porém a diversidade química destas moléculas fornece uma ampla variedade de compostos com propriedades específicas, que permitem aplicações comerciais em diversos setores industriais ${ }^{14}$.

Esta revisão tem o propósito de levantar dados sobre produção, aplicação e atualidades relacionadas à surfactina, o principal surfactante produzido por linhagens de Bacillus subtilis sendo que, apesar de ser um biossurfactante muito efetivo, poucos estudos foram realizados a respeito de suas aplicações. Além disso, suas características químicas e propriedades funcionais permitem evidenciar o grande potencial dessa substância para aplicação em diversos segmentos industriais.

\section{PROPRIEDADES QUÍMICAS}

A surfactina é conhecida por ter excepcional atividade superficial, reduzindo a tensão superficial da água $\left(20^{\circ} \mathrm{C}\right)$ de 72 para $27 \mathrm{mN} /$ $\mathrm{m}^{10,24-27}$ em concentrações menores de $20 \mu \mathrm{M}^{26}$, além de reduzir a tensão interfacial do sistema água/hexadecano de 43 para valores menores que $1 \mathrm{mN} / \mathrm{m}^{25,27}$. Quando é comparada a outros biossurfactantes $^{27,28}$ e a alguns surfactantes sintéticos, como dodecilsulfato de sódio (SDS) e brometo de trimetil amônio (BTA ${ }^{29}$, possui maior capacidade de reduzir a tensão superficial e interfacial e apresenta menores valores de concentração micelar crítica $(\mathrm{CMC})^{27-29}$.

A surfactina é produzida por várias cepas de Bacillus subtilis $^{10,21,30,31}$ e sua estrutura geral, demonstrada na Figura 1, é a de um peptídeo cíclico de sete aminoácidos ligados a uma cadeia de ácido graxo $\beta$-hidróxi, sendo que esta cadeia pode variar de 13 a 15 átomos de carbono, permitindo a existência de diferentes compostos homólogos e isômeros ${ }^{25,31,32}$. O principal ácido graxo conjugado é o ácido 3 hidroxi-13-metil-tetradecanóico ${ }^{31,32}$ ligado por ligação lactona, tal como os demais ${ }^{26}$.

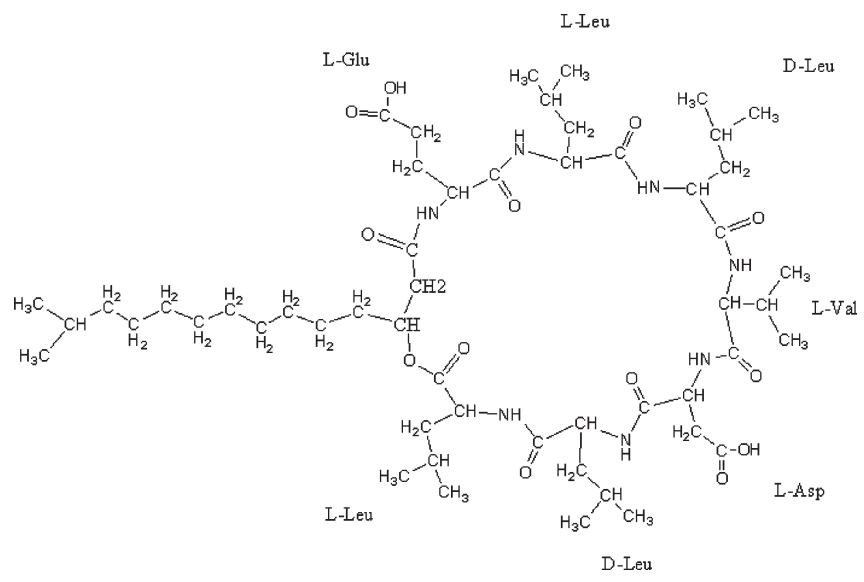

Figura 1. Estrutura da principal isoforma da surfactina

A surfactina natural é uma mistura de isoformas que se diferenciam ligeiramente em suas propriedades físico-químicas devido a variações no tamanho da cadeia, à ligação do seu componente hidroxi ácido graxo e a substituições dos aminoácidos componentes do anel ${ }^{31}$. Estas variações dependem da linhagem ${ }^{31,33}$ e das condições nutricionais e ambientais ${ }^{31,34}$, mais do que de determinação genética.
A atividade biológica da surfactina depende tanto da composição de aminoácidos e da sequiência do peptídeo como da natureza da sua parte lipídica ${ }^{31}$. As substituições de aminoácidos são responsáveis pelas mudanças significativas em suas propriedades causadas pela modificação da distribuição polar/apolar e/ou da acessibilidade de grupos carboxílicos a cátions. Estas modificações acarretam em diferenças na capacidade hemolítica, quelação de metais, CMC e atividade superficial ${ }^{25,26}$.

Vários experimentos têm demonstrado que a surfactina é bastante estável quando submetida a diversas condições. Os biossurfactantes produzidos por Bacillus sp são estáveis em concentrações de $\mathrm{NaCl}$ de 2 a $3 \%$, as quais são suficientes para inativar surfactantes convencionais ${ }^{35}$. O biossurfactante produzido pela cepa de Bacillus subtilis C9 apresentou amplo limite de estabilidade e manutenção de propriedades emulsificantes a limites variados de temperaturas $\left(20-100{ }^{\circ} \mathrm{C}\right.$ por $\left.1 \mathrm{~h}\right), \mathrm{pH}(5,0$ a 9,5) e concentrações salinas de $1.000 \mathrm{mM}$ de $\mathrm{NaCl}$ e $10 \mathrm{mM}$ de $\mathrm{CaCl}_{2}{ }^{29}$.

Utilizando-se outra linhagem, foi produzido surfactante com estabilidade a variações de temperatura $\left(100{ }^{\circ} \mathrm{C}\right.$ por $2 \mathrm{~h}, 121^{\circ} \mathrm{C}$ por $0,5 \mathrm{~h}$ e $135^{\circ} \mathrm{C}$ por $1 \mathrm{~h}$ ), de $\mathrm{pH} 6$ a 12 , em concentração salina $(15 \% \mathrm{NaCl})$ e em presença de enzimas proteolíticas (bromelina, ficina, papaína e tripsina) além de boas propriedades emulsificantes de óleos vegetais e hidrocarbonetos ${ }^{21}$.

A acidificação da solução para $\mathrm{pH}$ igual a 2 eleva a tensão superficial para $62 \mathrm{mN} / \mathrm{m}$, voltando para $27 \mathrm{mN} / \mathrm{m}$ com a neutralização, pH 6, mostrando a dependência das propriedades surfactantes da surfactina em relação ao $\mathrm{pH}^{27}$. Isto se deve ao fato de que em meio ácido a surfactina precipita sem, contudo, ter sua estrutura altera$\mathrm{da}^{21,27}$. Esta característica constitui em uma vantagem adicional pois, mesmo submetida a condições mais extremas de $\mathrm{pH}$, há manutenção da estrutura química original.

\section{PROPRIEDADES FUNCIONAIS E TOXICOLÓGICAS}

Um número crescente de investigações relativas às propriedades funcionais dos biossurfactantes colocam-nos como produtos de origem biotecnológica de real importância quanto às variadas aplicações. São propostas três funções principais para esses compostos: aumentar a área superficial de substratos hidrofóbicos insolúveis em água, aumentar a biodisponibilidade de substratos hidrofóbicos pelo aumento de sua solubilidade aparente e influenciar a adesão de microrganismos a superfícies. Essas funções têm forte influência na sobrevivência dos microrganismos produtores desses surfactantes no seu habitat natural (solo e rizosfera) ${ }^{5}$.

Assim como os demais biossurfactantes, os lipopeptídeos são capazes de alterar as propriedades físicas e/ou químicas de interfaces. Estes compostos podem atuar como antibióticos, agentes antivirais e antitumorais, imunomoduladores ou inibidores de enzimas e toxinas. O modo de ação de muitos desses compostos não foi esclarecido em detalhe até o momento, apesar de se saber que suas atividades de superfícies e de membrana desempenham um papel importante em diversos sistemas. Muitos surfactantes lipopeptídicos possuem potentes atividades antibióticas e foram submetidos a diversos estudos na descoberta de novos antibióticos ${ }^{5}$. Dentre os lipopeptídeos, a surfactina é o representante mais investigado ${ }^{36}$, pois apresenta baixa $\mathrm{CMC}$, alto poder de redução da tensão superficial $^{10,21,27,29,37}$, além de apresentar diversas funções biológicas, como demonstrado na Tabela 1.

Essas funções caracterizam a surfactina como molécula biologicamente ativa. Apesar dos mecanismos de ação da surfactina não estarem plenamente elucidados, presume-se que essas características sejam uma consequiência direta da interação membranal da surfactina e a alteração das propriedades de bicamada. Mais especi- 
Tabela 1. Algumas das principais funções biológicas da surfactina

\begin{tabular}{lc}
\hline Função da surfactina & Ref. \\
\hline Bactericida & $8,21,36$, \\
& $37,38,39$ \\
Fungicida & $21,36,40$ \\
Antiviral & $21,37,41$ \\
Agente antitumoral & 21,42 \\
Inibidor da formação de coágulos fibrinosos & 41,43 \\
Antimicoplasmático & 40,44 \\
Veículo para administração de drogas via pulmonar & 45,46 \\
\hline
\end{tabular}

ficamente, parece claro que essas propriedades da surfactina estão principalmente relacionadas à sua capacidade de alterar a integridade membranal, como consequiência do estabelecimento de fortes interações com os constituintes fosfolipídicos da membrana celular ${ }^{45}$. Estudos sobre os mecanismos moleculares de permeabilização de membrana através da incorporação da surfactina demonstraram haver perda do conteúdo vesicular através da desestabilização lipídica ou formação de poros intra membranais ${ }^{38,47}$. Recentemente, foi demonstrado que certos tipos de peptídeos cíclicos são capazes de inativar bactérias gram-positivas e gram-negativas, através da autoformação de sistemas tubulares em membranas lipídicas ${ }^{38}$.

As propriedades da surfactina também são base para a explicação de sua ação anticarcinogênica. Foi proposto que a surfactina tem a capacidade de, ao atingir o interior da célula, promover ruptura da membrana plasmática ${ }^{28}$. Mostrou atividade antitumoral contra células com carcinoma de Ehrlich $^{39}$; atividade antiproliferativa em experimentos com células dos cânceres de ovário, renal, de próstata, de cólon, de pulmão, de mama, de mama residente e melanoma; atividade citostática e citotóxica a todos os carcinomas investigados ${ }^{21}$.

A surfactina também é capaz de inibir a formação de biofilmes de outras bactérias, até mesmo da patógena Salmonella enterica. As ações antimicrobianas e antifúngicas de lipopeptídeos foram vantajosas para células de $B$. subtilis ao eliminar competidores do mesmo habitat ${ }^{36}$.

Apesar dos biossurfactantes lipopeptídicos agirem na membrana celular de microrganismos de modo semelhante aos surfactantes sintéticos ${ }^{5}$, a atividade biológica da surfactina de uma linhagem de $B$. subtilis cultivada em manipueira mostrou-se mais elevada que a surfactina comercial, em ensaios com diversas linhagens de microrganismos (entre os quais Staphylococcus aureus e Salmonella

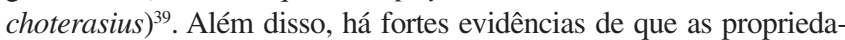
des de barreiras da membrana podem ser danificadas em áreas onde os oligômeros da surfactina interagem com fosfolipídeos. Isso causa flutuações estruturais que podem ser o princípio de ação dos antibióticos e de outros efeitos biológicos importantes desse lipopeptídeo. Estes tipos de peptídeos atuam rapidamente sobre a integridade membranal, assim como em outros processos vitais e podem, talvez, constituir a próxima geração de antibióticos ${ }^{37}$.

O potencial dos surfactantes peptídicos pode ser evidenciado através da demonstração de propriedades das proteínas surfactantes humanas A e D, ao proteger ratos contra hipersensitividade pulmonar induzida por A. fumigatus e produtos alergênicos. As proteínas surfactantes podem interagir com os antígenos glicosilados e alergênicos de A. fumigatus, inibindo a ligação específica da IgE com o alergênico e serem capazes de bloquear a liberação de histamina sintetizada de basófilos ${ }^{42}$.

Outra aplicação proposta é a da facilitação da absorção de fármacos utilizando o pulmão como sítio de entrada. Esse órgão possui muitas características favoráveis para administração de drogas pois apresen- ta baixa atividade enzimática intrínseca, grande área de absorção $\left(100 \mathrm{~m}^{2}\right)$, é bem irrigado pelos vasos sanguíneos, possui fina camada alveolar do epitélio $(0,1-0,2 \mu \mathrm{m})$ e curta distância para passagem arsangue $^{45}$. Os efeitos da surfactina na absorção de insulina em pulmão de ratos foram examinados. A biodisponibilidade do peptídeo administrado pela rota intratraqueal como solução contendo 1 ou $10 \mathrm{mM}$ de surfactina foi 15,1 e $80,0 \%$, respectivamente. Dados relativos à toxicidade não são apresentados no relato ${ }^{46}$.

A atividade antiviral da surfactina foi determinada para uma larga gama de vírus. Experimentos in vitro mostraram que a surfactina inativou eficazmente o vírus causador de herpes, assim como o retrovirus e outros vírus de RNA e DNA compactados. Surpreendentemente, não foi inativado o vírus Semliki Forest, um vírus envelopado utilizado como modelo para vírus da hepatite $\mathrm{C}$. Concentrações maiores que $80 \mathrm{mM}$ levaram a uma redução nas concentrações dos vírus ${ }^{41}$.

A ruptura total das membranas lipídicas virais e parcial dos capsídeos sugere que a ação antiviral seja devida à interação físico-química do surfactante com a membrana viral lipídica. A surfactina pode ser útil em aplicações relacionadas ao aumento da segurança de produtos biotecnológicos e farmacêuticos, tais como derivados de sangue e produtos obtidos de culturas de células, os quais possuem risco de transmitir doenças, como o vírus da hepatite B, HIV ou Herpes simplex. Entretanto, o potencial da surfactina parece ser dependente do ambiente, pois a atividade da surfactina contra vírus decresce com um incremento da relação proteína/ lipídeo no meio de reação. Dessa forma, não deve ser útil para melhora da segurança contra vírus em produtos com alta concentração protéica ${ }^{41}$.

Estudos de toxicidade in vivo em ratos demonstraram que a $\mathrm{LC}_{50}$ da surfactina é $200 \mathrm{mg} / \mathrm{kg}$ em aplicações intramusculares e maior que $4 \mathrm{~g} / \mathrm{kg}$ em aplicações orais ${ }^{30}$. Devido a essa baixa toxicidade in vivo, talvez não seja necessário que a surfactina seja completamente removida de produtos. Por outro lado, a surfactina possui efeito hemolítico e inibe a formação de coágulo fibrinoso, portanto, deve ser removida quando utilizada durante o processo produtivo de certos produtos ${ }^{41}$.

Entretanto, sabe-se que os biossurfactantes, em geral, possuem baixa toxicidade, podendo ser aplicados em alimentos, cosméticos e produtos farmacêuticos. Bacillus amyloliquefaciens e outros membros do grupo do Bacillus subtilis são considerados como seguros. Alguns produtos celulares de linhagens de Bacillus possuem o status 'GRAS' ("Generally Recognized as Safe"). Alguns casos podem ser citados, como a preparação enzimática de pectato-liase de Bacillus subtilis (GRAS n $\left.{ }^{\circ} 114\right), \alpha$-amilase derivada de Bacillus licheniformis (GRAS $\mathrm{n}^{\circ}$ 79) e pululanase de Bacillus licheniformis $\left(\text { GRAS } n^{\circ} 72\right)^{48}$. Apesar disso, B. subtilis e B. licheniformis parecem estar implicados em alguns casos de envenenamentos fatais por alimentos ${ }^{49}$.

Demonstrou-se que o tratamento com surfactina melhorou as taxas de proliferação e mudanças morfológicas de células mamárias que foram contaminadas com micoplasma ${ }^{44}$, sem efeitos deletérios significantes no metabolismo celular e na proliferação de células em cultura ${ }^{50}$.

Relatou-se que a surfactina C, nas concentrações de 3 a $20 \mu \mathrm{M}$, aumenta a ativação de pró-uroquinase na presença de plasminogênio (as ativações do plasminogênio e da pró-uroquinase são mecanismos importantes nas etapas de iniciação e propagação da atividade fibrinolítica local ${ }^{46}$. Isso sugere uma possível aplicação para surfactina em terapia trombolítica. Além disso, a surfactina tem vantagens sobre outros agentes trombolíticos disponíveis, pois os mesmos apresentam efeitos colaterais e, possuem potencial apenas para uso a curto prazo ${ }^{50}$. 


\section{BIOSSURFACTANTES NA INDÚSTRIA DE ALIMENTOS: ASPECTOS TECNOLÓGICOS}

Biossurfactantes são de grande interesse por suas propriedades físico-químicas e biológicas que podem ser exploradas nas indústrias farmacêutica, de óleos minerais ${ }^{24} \mathrm{e}$ de alimentos ${ }^{51}$. A propriedade de formação e estabilização de emulsões é a principal característica a ser influenciada pela adição de biossurfactantes em alimentos ${ }^{4,6,21,38,39,52}$. De forma geral, a função dos emulsificantes em alimentos é promover a estabilidade da emulsão, controlando a aglomeração de glóbulos de gordura e estabilizando sistemas aerados ${ }^{53,54}$.

Por definição, uma emulsão é um sistema heterogêneo, consistindo de ao menos um líquido imiscível (fase interna descontínua) disperso em outro (fase externa contínua) em forma de pequenas gotas, com o diâmetro que, em geral, excede $0,1 \mu \mathrm{m}^{54}$. Tais sistemas possuem uma estabilidade mínima, a qual pode ser aumentada por aditivos surfactantes, sólidos finamente divididos etc ${ }^{52,53}$, que atuam reduzindo a tensão interfacial, diminuindo a energia na superfície entre as duas fases e prevenindo a coalescência das partículas através da formação de barreiras estéricas e elestrostáticas ${ }^{53}$. Exemplos de emulsões naturais são o leite e a gema de ovo. Exemplos de alimentos processados, que são emulsões, são creme de leite, manteiga, margarina, maionese, molhos para salada, salsicha, lingüiça, sorvetes, bolos, chocolate, recheios ${ }^{52}$ e produtos instantâneos ${ }^{54}$.

Outras aplicações para os emulsificantes são descritas, entre elas: melhorar a textura e vida de prateleira de produtos contento amido, pela formação de complexos com os componentes destes; modificar as propriedades reológicas da farinha de trigo, pela interação com o glúten; melhorar a consistência e textura de produtos à base de gorduras, pelo controle de polimorfismo e da estrutura cristalina das gorduras $^{3,54}$ além de promover a solubilização de aromas $^{6}$.

Algumas vantagens da aplicação de biossurfactantes em alimentos podem ser citadas: estes compostos podem ser produzidos sob aplicação de procedimentos relativamente simples e baratos; novos tipos de surfactantes, que não são facilmente sintetizados por processo químico, podem ser obtidos; possuem um aspecto ecologicamente correto, devido à sua completa biodegradabilidade; para aplicações específicas, diferentes propriedades do mesmo composto podem ser utilizadas (como a combinação do efeito emulsificante com antibiótico $)^{28}$, bem como seu potencial para utilização como ingrediente com propriedades funcionais ${ }^{29}$.

Apesar da aplicação potencial, a indústria de alimentos não utiliza ainda os biossurfactantes como aditivos em larga escala. Muitas propriedades dos biossurfactantes, assim como sua regulação em relação à aprovação como novo ingrediente para alimentos, têm que ser resolvidas. A elaboração de testes e avaliação de qualquer novo ingrediente é requerida de acordo com os regulamentos do "U. S. Food and Drug Administration" e este processo pode ser longo. Os fatores a serem considerados nesta avaliação estão relacionados a questões nutricionais, funcionais, sensoriais, biológicas e toxicológicas do novo ingrediente, além disso outros fatores devem ser considerados, tais como fatores econômicos, quando comparados aos surfactantes sintéticos para o mesmo uso, aceitação pelo consumidor, regulação legal e hábitos alimentares dos consumidores ${ }^{52}$.

Apesar das restrições citadas, a utilização de biossurfactantes em alimentos mostra-se promissora quando são consideradas algumas aplicações já descritas na literatura. No Japão, onde restrições legais relativas ao uso de novos componentes naturalmente produzidos em processos biotecnológicos na indústria de alimentos não são tão rígidas, soforolipídios foram patenteados como aditivos para farinha de trigo ${ }^{55}$, parede celular de Saccharomyces uvarum hidrolizada e liofilizada aplicada em margarinas ${ }^{56}$, bem como ramnolipídos de Pseudomonas aeruginosa para aplicações cosméticas e alimentícias ${ }^{57-59}$. Além disso, outro relato apontou possíveis aplicações de biossurfactantes em alimentos: Emulsan e Paraemulsan de Acinetobacter calcoaceticus combinados com emulsificantes sintéticos ${ }^{60}$.

A manoproteína produzida por Saccharomyces cerevisiae pode estabilizar emulsões água/óleo para produção de maionese, biscoitos, bolos, produtos cárneos (salsichas), sorvetes, entre outros. É produzida através de um processo biotecnológico simples, de larga escala e baixo custo. Além de ser estável em uma larga faixa de $\mathrm{pH}$ (3-11), seu subproduto pode ser utilizado para alimentação animal ou produção de meios de cultura ${ }^{61}$.

Ramnolipídeos produzidos por Pseudomonas aeruginosa em processos de fermentação descontínuos e semi-contínuos têm demonstrado alta produtividade, tornando este método viável para a produção de L-ramnose em escala comercial. A ramnose tem aplicação industrial como matéria-prima na produção de alguns compostos orgânicos ${ }^{58}$.

Leveduras Candida utilis, Candida valida, Hansenula anomala, Rhodospiridium diobovatum e Rrhodotorula graminis, a alga vermelha Porphiridium cruentum e as bactérias Klebsiella sp e Acinetobacter calcoaceticus foram identificadas como bons produtores de bioemulsificantes extracelulares, com melhor atividade estabilizante que a goma arábica e a carboximetilcelulose. O biossurfactante produzido por Candida utilis, aplicado como emulsificante em molhos para salada, mostrou-se promissor para ser investigado como novo ingrediente para indústria de alimentos ${ }^{62}$.

Em detrimento às propriedades da surfactina, relatos de sua aplicação na indústria de alimentos são escassos. Contudo, relatase que um surfactante produzido por linhagem de B. subtilis, utilizando solução de $1,0 \mathrm{mg} / \mathrm{mL}$ de produto bruto em água, demonstrou capacidade de formar emulsões estáveis de óleos comestíveis, por ex., óleos de buriti (Mauria flexuosa), maracujá (Passiflora alata), cupuaçu (Theobroma grandiflora), babaçu (Attalea speciosa), linhaça (Linum usitatissimum), castanha do Pará (Bertholetia excelsa), palma (Elaeis guineensis dura), soja (Glycine max), girassol (Helianthus annus), canola (Brassica napus) e oliva $(\text { Olea europaca })^{21}$.

\section{PERSPECTIVAS PARA PRODUÇÃO DA SURFACTINA UTILIZANDO RESÍDUOS AGROINDUSTRIAIS}

A surfactina ainda não é explorada comercialmente devido, principalmente, ao seu elevado custo de produção ${ }^{37}$. Contudo, as propriedades de formar emulsões estáveis de óleos comestíveis em água $^{21}$ e de reduzir fortemente a tensão superficial, mesmo em baixas concentrações ${ }^{10,26-28}$, têm especial significado quando se leva em consideração a viabilidade econômica de formulações que contenham estas substâncias, haja visto que alguns produtos com alto valor agregado poderiam absorver os altos custos originados a partir da adição destes compostos ${ }^{52}$. Estes fatos sugerem o grande potencial de aplicação industrial para os biossurfactantes.

A fim de reduzir os custos de produção para ampliação das possibilidades de aplicação, o uso de resíduos industriais como meio de cultura é uma alternativa praticável, uma vez que a matéria-prima representa $30 \%$ de custos totais em um processo biotecnológico ${ }^{63}$.

O processo produtivo da surfactina ainda não está bem estabelecido para aplicação direta em escala industrial, sendo os fatores econômicos os principais empecilhos. Levando-se em consideração que milhões de toneladas de resíduos danosos ao meio ambiente são gerados, a utilização dos mesmos em processos biotecnológicos parece ser uma alternativa plausível, principalmente quando se considera a utilização de uma grande variedade de resíduos agroindustriais como matéria-prima para processos biotecnológicos ${ }^{64}$. Deste modo, a utilização de resíduos agroindustriais para 
produção de biossurfactantes é um dos passos na direção da viabilização da implantação desses processos em escala industrial.

Por outro lado, no caso da produção biotecnológica de surfactantes, é necessário um correto balanço de nutrientes para promover condições adequadas de desenvolvimento e produção. Dessa forma, a utilização de resíduos com alto conteúdo de carboidratos e lipídeos parece ser uma opção adequada para produção de biossurfactantes ${ }^{65}$.

Os efluentes do processamento de batatas caracterizam-se como potenciais substituintes de substratos convencionais sintéticos, pois são geralmente ricos em fonte de carbono na forma de amido e açúcares, nitrogênio e minerais. Foi investigada a produção de surfactina por linhagem de Bacillus subtilis 21332 desenvolvida em meio contendo efluentes sólidos do processamento de batata. O rendimento final de surfactina foi $66 \%$ inferior se comparado com o rendimento em meio de amido de batata otimizado ${ }^{66}$. A utilização de hidrolisados de turfa por uma linhagem de Bacillus subtilis para produção de surfactina é relatada. Os autores descreveram a utilização dos compostos gerados a partir da hidrólise ácida do material. A produção do biossurfactante parece estar relacionada com a proporção entre carbono e nitrogênio do meio de cultivo. Relata-se ainda que a produção do biossurfactante foi tão eficiente quanto a produção em meio sintético. Ressalta-se que diferenças na composição do meio refletiram em diferenças nas curvas de tensão superficial ${ }^{67}$. Substratos adicionais foram sugeridos para produção de biossurfactante, tais como melaço e soro de leite ${ }^{68}$. Além desses resíduos citados, há descrição da utilização de outros resíduos, como rejeitos do processamento de óleos ${ }^{69}$ e resíduos do processamento de soja ${ }^{70}$.

Outro exemplo de substrato com altos teores de fontes de carbono é a manipueira, a qual é originada da prensagem das raízes de mandioca para fabricação de farinha e de fécula. Este efluente é, geralmente, descarregado no ambiente, resultando em grande problema ambiental ${ }^{68}$.

Alguns relatos sugerem a manipueira como substrato para produção biotecnológica, como a produção de biomassa oleaginosa por Trichosporon $\mathrm{sp}^{71} \mathrm{e}$ ácido cítrico por Aspergillus niger ${ }^{72}$. No caso da produção de biossurfactante, várias linhagens de Bacillus subtilis foram testadas segundo suas habilidades em utilizar a manipueira para produção de surfactina ${ }^{21,37,68,73}$. Quando comparada com meio sintético e com alguns resíduos, tais como melaço e soro de leite, segundo a tensão superficial final do meio de cultura, a manipueira foi o substrato no qual os menores valores de tensão foram encontrados. Os valores próximos a $26 \mathrm{mN} / \mathrm{m}$ encontrados indicam que a manipueira está entre os meios de cultura mais adequados para produção de biossurfactante ${ }^{37,73}$.

\section{CONCLUSÕES}

Apesar de, até o momento, existirem poucos estudos a respeito de aplicações industriais da surfactina, suas propriedades químicas, tecnológicas e funcionais indicam fortes possibilidades de uso neste setor.

Do ponto de vista químico, propriedades como detergência, emulsificação, capacidade espumante, solubilização e dispersão de fases da surfactina geram possibilidades para inúmeras aplicações em diversos produtos alimentícios, tais como produtos de panificação, aromas, laticínios etc.

Associadas a isso, algumas de suas vantagens tecnológicas como estabilidade a diversas condições de processamento, bem como na formação de emulsões estáveis, fazem da surfactina um potencial ingrediente industrial.

Adicionalmente, levando-se em conta as atuais preocupações dos consumidores com relação à alimentação e saúde, a aplicação da surfactina em alimentos mostra-se favorável a essa tendência, uma vez que evidências demonstram possíveis atividades funcionais desse biossurfactante como agente preventivo a alguns tipos de doença. Estudos toxicológicos apontam baixa toxicidade in vivo.

Apesar de muitos elementos favoráveis à sua aplicação, a indústria de alimentos não faz uso de biossurfactantes devido, principalmente, aos custos envolvidos em seu processo produtivo. Recentemente, algumas possibilidades têm surgido para redução de custos de produção dos biossurfactantes em geral. A utilização de resíduos industriais como meio de cultura para microrganismos produtores de biossurfactantes parece ser uma alternativa possível.

Levando-se em conta as inúmeras características e propriedades apresentas pela surfactina, a redução dos custos de sua produção tornaria possível a aplicação industrial desses compostos em um futuro próximo.

\section{REFERÊNCIAS}

1. Jönsson, B.; Lindman, B.; Holmberg, K.; Kronberg, B. Em Surfactants and Polymers in Aqueous Solutioneds; Jönsson, B.; Lindman, B.; Holmberg, K.; Kronberg, B., eds.; Wiley: New York, 1998, cap. 1.

2. Waters, J. Em Recent Developments in the Analysis of Surfactants; Porter, M. R., ed.; Crown House: UK, 1991, cap. 6.

3. Banat, I. M.; Biofutur 2000, 198, 44.

4. Nitschke, M.; Pastore, G. M.; Quim. Nova 2002, 25, 772.

5. Cameotra, S. S.; Makkar, R. S.; Curr. Opin. Microbiol. 2004, 7, 262.

6. Banat, I. M.; Makkar, R. S.; Cameotra, S. S.; Appl. Microbiol. Biotechnol. 2000, 53, 495.

7. Lin, S.; J. Chem. Technol. Biotechnol. 1996, 66, 109.

8. Maier, R. M.; Adv. Appl. Microbiol. 2003, 52, 101.

9. Jarvis, F. G.; Johnson, M. J.; J. Am. Chem. Soc. 1949, 71, 4124.

10. Arima, K.; Kakinuma, A.; Tamura, G.; Biochem. Biophys. Res. Commun. 1968, 31,488

11. Kakinuma, A.; Ouchida, A.; Shima, T.; Sugino, H.; Isono, M.; Tamura, G.; Arima. K.; Agric. Biol. Chem. 1969, 33, 1669; Kakinuma, A.; Hori, M.; Isono, M.; Tamura, G.; Arima. K.; Agric. Biol. Chem. 1969, 33, 971; Kakinuma, A.; Sugino, H.; Isono, M.; Tamura, G.; Arima, K.; Agric. Biol. Chem. 1969, 33, 976.

12. Itoh, S.; Honda, H.; Tomita, F.; Suziki, T.; J. Antiobiot. 1971, 24, 855.

13. Prince, R. C.; Crit. Rev. Microbiol. 1993, 19, 217.

14. van Dyke, M. I.; Lee, H.; Trevors, J. T.; Biotechnol. Adv. 1991, 9, 241.

15. Zajic, J. E.; Seffens, W.; CRC Crit. Rev. Biotechnol. 1984, 1, 87.

16. Desai, J. D.; Desai, A. J. Em Biosurfactants: production, properties, applications; Kosaric, N., ed.; Marcel Decker: New York, 1993, cap. 3.

17. Steller, S.; Vater, J.; J. Chromatogr., B: Anal. Technol. Biomed. Life Sci. 2000, 737, 267.

18. Cubitto, M. A.; Morán, A. C.; Commendatore, M.; Schiarello, M. N.; Baldini, M. D.; Siñeriz, F.; Biodegradation 2004, 15, 281.

19. Morán, A. C.; Olivera, N.; Commendatore, M.; Esteves, J. L.; Siñeriz, F.; Biodegradation 2000, 11, 65

20. Olivera, N. L.; Commendatore, M. G.; Moran, A. C.; Esteves, J. L.; J. Ind. Microbiol. Biotechnol. 2000, 25, 70.

21. Costa, G. A. N.; Dissertação de Mestrado, Universidade Estadual de Campinas, Brasil, 2005.

22. Awashti, N.; Kumar, A.; Makkar, R.; Cameotra, S.; J. Environ. Sci. Health, Part B 1999, 34, 793.

23. Mulligan, C. N.; Yong, R. N.; Gibbs, B. F.; Environ. Sci. Technol. 1999, 33,3812 .

24. Bognolo, G.; Colloids Surf. 1999, 12, 41

25. Lang, S.; Curr. Opin. Colloid Interface Sci. 2002, 7, 12.

26. Peypoux, F.; Bonmatin, J. M.; Wallach, J.; Appl. Microbiol. Biotechnol. 1999, 51, 553

27. Cooper, D. G.; Macdonald, C. R.; Duff, S. J. B.; Kosaric, N.; Appl. Environ. Microbiol. 1981, 42, 408.

28. Hafenburg, D.; Hommel, R.; Kleber, H.; Adv. Biochem. Eng. 2003, 33, 53.

29. Kim, H.; Yoon, B.; Lee, C.; Suh, H.; Oh, H.; Katsuragi, T.; Tani, Y.; J. Ferment. Bioeng. 1997, 84, 41

30. Arima, K.; Kakinuma, A.; Tamura, G.; German Patent OS 1,903,987 1968.

31. Kowall, M.; Vater, J.; Kluge, B.; Stein, T.; Franke, P.; Ziessow, D.; J. Colloid Interface Sci. 1998, 204, 1.

32. Kluge, B.; Vater, J.; Salnikow, J.; Eckart, K.; FEBS Lett. 1988, $231,107$.

33. Hsieh, F.; Li, M.; Lin, T.; Kao, S.; Cur. Microbiol. 2004, 49, 186.

34. Davis, D. A.; Lynch, H. C.; Varley, J.; Enzyme Microb. Technol. 1999, 25, 322. 
35. Lin, S. C.; Goursaud, J. C.; Kramer, P. J.; Georgiou G.; Sharma, M. M. Em Microbial Enhacement of Oil Recovery - Recent Advances; Donaldson, E. C., ed.; Elsevier Science Publishers: Amsterdan, 1990.

36. Stein, T.; Mol.. Microbiol. 2005, 56, 845.

37. Nitschke, M.; Tese de Doutorado, Universidade Estadual de Campinas, Brasil, 2004.

38. Carrillo, C.; Teruel, J. A.; Aranda, F. J.; Ortiz, A.; Biochem. Biophys. Acta 2003, 1611, 91 .

39. Nitschke, M.; Haddad, R.; Costa, G. A.; N.; Gilioli, R.; Meurer, E. C.; Gatti, M. S.; Eberlin, M. N.; Höehs, N. F.; Pastore, G. M.; Food Sci. Biotechnol. 2004, 13, 591.

40. Madan, T.; Kishore, U.; Singh, M.; Strong, P.; Clark, H.; Hussain, E. M.; Reid, K. B. M.; Sarma, P. U.; J. Clin. Invest. 2001, 107, 467.

41. Vollenbroich, D.; Özel, M.; Vater, J.; Kamp, R. M.; Pauli, G.; Biologicals 1997, 25, 289

42. Kameda, Y.; Oira, S.; Matsui, K.; Kanatomo, S.; Hase, T.; Chem. Pharm. Bull. 1974, 22, 938.

43. Kikuchi, T.; Hasumi, K.; Biochem. Biophys. Acta 2002, 1596, 234.

44. Vollenbroich, D.; Pauli, G.; Ozel, M.; Vater, J.; Appl. Environ. Microbiol. 1997, 63, 44.

45. Hussain, A.; Arnold, J. J.; Khan, M. A.; Ahsan, F.; J. Controlled Release 2004, 94, 15

46. Okumura, K.; Iwakawa, S.; Yoshida, S.; Seki, T.; Komada, F.; Int. J. Pharm. 1992, 88, 63.

47. Sheppard, J. D.; Jumarie, C.; Cooper, D. G.; Laprade, R.; Biochem. Biophys. Acta 1991, 1064, 13.

48. http://www.cfsan.fda.gov, acessada em Fevereiro 2006.

49. Mikkola, R.; Anderson, M. A.; Grigoriev, P.; Teplova, V. V.; Saris, N. L.; Rainey, F. A.; Mirja S.; Salkinoja-Salonen, M. S.; Arch. Microbiol. 2004, $181,314$.

50. Singh, P.; Cameotra, S. S.; Trends Biotechnol. 2004, 22, 142.

51. Desai, J. D.; Banat, I. M.; Microbiol. Molec. Biol. Rev. 1997, 61, 47.

52. Velikonja, N.; Kosaric, N. Em Biosurfactants: production, properties, applications; Kosaric, N., ed.; Marcel Decker: New York, 1993, cap. 16.

53. Bernheimer, A. W.; Avigad, L.; J. Gen. Microbiol. 1970, 6, 361.
54. Kachholz, T.; Schingmann, M. Em Biosurfactants and Biotechnology; Kosaric, N.; Cairns, W. L.; Gray, N. C. C., eds.; Marcel Dekker: New York, 1987, cap. 7.

55. Shigeta, A.; Yamashita, A.; Jpn. Kokai Tokkyo Koho 61 205,449 1986.

56. Ohata, K.; Kamata, K.; Jpn. Kokai Tokkyio Koho 61 227, 8271986

57. Ishigami, Y.; Gama, Y.; Nagahara, H.; Motomiya, T.; Yamagushi, M; Jpn. Kokai Tokkyo Koho 63 182,029 1988.

58. Daniels, L.; Linhardt, R. J.; Bryan, B.A.; Mayerl, F.; Pickenhagen, W.; European Patent Appl. 282,942 1988.

59. Linhardt, R. J.; Bakhil, R.; Daniels, L.; Mayerl, F.; Pickenhagen, W. Biotechnol. Bioeng. 1989, 33, 365.

60. Miyata, K.; Tsuchida, T.; Tawara, K.; Jpn. Kokai Tokkyo Koho 62 155, 931 1987.

61. Torabizadeh, H.; Shajaosadati, S. A.; Tehrani, H. A.; Lebensm.-Wiss. $U$ Technol. 1996, 29, 734.

62. Shepherd, R.; Rockey, J.; Sutherland, I. M.; Roller, S.; J. Biotechnol. 1995 , 40, 207.

63. Cameotra, S. S.; Makkar, R, S.; Appl. Microbiol. Biotechnol. 1998, 50, 520.

64. Pandey, A.; Soccol, C. R.; Nigam, P.; Brand, D.; Mohan, R.; Roussos, S.; Biochem. Eng. J. 2000, 6, 153.

65. Makkar, R. S.; Cameotra, S. S.; Appl. Microbiol. Biotechnol. 2002, $58,428$.

66. Thompson, D. N.; Fox, S. L.; Bala, G. A.; Appl. Biochem. Biotechnol. 2000, 84, 917.

67. Sheppard, J. D.; Mulligan, C. N.; Appl. Microbiol. Biotechnol. 1987, 27, 110 .

68. Nitschke, M.; Ferraz, C.; Pastore, G. M.; Braz. J. Microbiol. 2004, 35, 81.

69. Mercade, M. E.; Manresa, M. A.; Robert, M.; Espuny, M. J.; Andres, C.; Guinea, J.; Bioresour. Technol. 1993, 43, 1.

70. Ohno, A.; Takashi, A.; Shoda, M.; Biotechnol. Bioeng. 1995, 47, 209

71. Wosiacki, G.; Fioretto, A. M. C.; Almeida, M. M.; Cereda, M. P. Em Manejo, uso e tratamento de subprodutos da industrialização da mandioca; Cereda, M. P., ed.; Fund. Cargill: São Paulo, 2000, cap. 12

72. Cabello, C.; Leonel, M.; Em ref. 71, cap. 9.

73. Pastore, G. M.; Santos, C. F. C.; Nitschcke, M.; Br. PI 0303853-0 2003 